\title{
Determinação dos tipos de resistência a Spodoptera cosmioides (Walker) (Lepidoptera: Noctuidae) em genótipos de soja
}

\section{Determination of the resistance types to Spodoptera cosmioides (Walker) (Lepidoptera: Noctuidae) in soybean genotypes}

\author{
Arlindo Leal Boiça Júnior ${ }^{1 *}$; Daline Benites Bottega²; Bruno Henrique \\ Sardinha de Souza ${ }^{2}$; Nara Elisa Lobato Rodrigues ${ }^{2}$; Victor Michelin ${ }^{3}$
}

\section{Resumo}

O objetivo do presente trabalho foi avaliar os tipos de resistência de genótipos de soja a Spodoptera cosmioides (Walker) em laboratório. Os genótipos de soja testados foram: 'IAC 100' (padrão resistente), 'BR16' (padrão suscetível), 'Dowling', PI 227687, PI 274454, 'IGRA RA 626 RR', PI 227682, 'BRSGO 8360', 'IGRA RA 516 RR' e 'P 98Y11 RR'. Foram realizados testes de não preferência para alimentação com e sem chance de escolha utilizando-se duas lagartas recém-eclodidas por genótipo ou uma lagarta de $3^{\circ}$ instar por genótipo em ambos os testes. Avaliou-se a atratividade das lagartas em diferentes intervalos de tempo, e ao término dos experimentos, quantificou-se a área foliar consumida. No teste de antibiose, lagartas recém-eclodidas foram individualizadas em placas de Petri, onde foram fornecidos folíolos dos genótipos durante toda a fase larval, e os seguintes parâmetros biológicos foram avaliados: período e viabilidade de larvas, pupas e total (larvas + pupas), peso de lagartas e de pupas, razão sexual e longevidade dos adultos. Em geral, nos testes de preferência para alimentação, não se verificaram diferenças significativas no consumo foliar entre os genótipos. No ensaio de antibiose, os genótipos PI 227687, PI 227682 e 'IAC 100' proporcionaram 100\% de mortalidade larval e os menores pesos de lagartas, variando entre 37,65 a $85,56 \mathrm{mg}$. Os genótipos de soja testados não apresentam resistência do tipo não preferência para alimentação a S. cosmioides e PI 227687, PI 227682 e 'IAC 100' destacaram-se por serem portadores de antibiose.

Palavras-chave: Não preferência, antibiose, lagarta-das-vagens, Glycine max

\begin{abstract}
The aim of this work was to evaluate the resistance types in soybean genotypes to Spodoptera cosmioides (Walker) in laboratory. Soybean genotypes assessed were as follows: 'IAC 100' (resistance standard), 'BR16' (susceptible standard), 'Dowling', PI 227687, PI 274454, 'IGRA RA 626 RR', PI 227682, 'BRSGO 8360', 'IGRA RA 516 RR' and 'P 98Y11 RR'. Free-choice and no-choice feeding non-preference tests were done using two newly-hatched larvae per genotype or one third-instar larva per genotype in both tests. Larvae attractiveness was evaluated in different times, and at the end of the experiments the leaf area consumed was quantified. In the antibiosis test, newly-hatched larvae were individualized into Petri dishes, where leaflets of the genotypes were offered over the larval stage, and the following biological parameters were assessed: period and viability of larvae, pupae and overall
\end{abstract}

1 Prof. Dr., Faculdade de Ciências Agrárias e Veterinárias, Universidade Estadual Paulista "Júlio de Mesquita Filho", UNESP, Jaboticabal, SP. E-mail: aboicajr@fcav.unesp.br

2 Drs. em Entomologia Agrícola pela Faculdade de Ciências Agrárias e Veterinárias, UNESP, Jaboticabal, SP. E-mail: daline4@ bol.com.br; souzabhs@gmail.com; naraelr@hotmail.com

3 Discente do Curso de Graduação em Agronomia, Faculdade de Ciências Agrárias e Veterinárias, UNESP, Jaboticabal, SP. E-mail: vi_michelin@hotmail.com

* Autor para correspondência 
(larvae + pupae), weight of larvae and pupae, sex ratio and adults longevity. Overall, in the feeding preference tests, significant differences were not found in leaf consumption among the genotypes. In the antibiosis assay, genotypes PI 227687, PI 227682 and 'IAC 100' caused 100\% larval mortality and the lowest weight of larvae, ranging between 37.65 and $85.56 \mathrm{mg}$. All soybean genotypes evaluated do not exhibit feeding non-preference type resistance to $S$. cosmioides, and PI 227687, PI 227682 and 'IAC 100 ' highlighted for possessing antibiosis.

Key words: Non-preference, antibiosis, armyworm, Glycine max

\section{Introdução}

A cultura da soja, Glycine $\max (\mathrm{L}$.$) Merril,$ se destaca como uma das mais importantes para o Brasil, que colheu cerca de 81,5 milhões de toneladas de soja no ano agrícola 2012/2013, em uma área cultivada de 27,7 milhões de hectares. Estima-se que a safra 2013/2014 ultrapasse os 90 milhões de toneladas produzidos, representando um aumento de quase $10 \%$ em relação à safra anterior (CONAB, 2014).

Dentre os fatores que podem influenciar adversamente o rendimento e a qualidade da produção da soja, estão as lagartas desfolhadoras pertencentes à ordem Lepidoptera, com destaque para Spodoptera cosmioides (Walker) (Lepidoptera: Noctuidae), cuja infestação tem sido cada vez mais frequente nas últimas safras (SANTOS et al., 2010), principalmente devido à presença de sistemas agrícolas constituídos pelas culturas de soja, algodão e milho cultivados em extensas áreas de monocultivo ou em sucessão, proporcionando contínuo suprimento alimentar para os insetos polífagos (SANTOS et al., 2009).

A espécie $S$. cosmioides, que há poucos anos atrás apresentava ocorrência esporádica na cultura da soja, durante os últimos anos tem sido considerada uma das pragas-chave em certas regiões produtoras do cerrado brasileiro (SANTOS, 2007). As lagartas de $S$. cosmioides danificam diretamente as vagens de soja quando as plantas se encontram no estádio reprodutivo (PANIZZI; BUENO; SILVA, 2012), e quando o ataque se dá nas folhas, o consumo é aproximadamente o dobro em relação ao consumo foliar de cada uma das demais espécies de lagartas desfolhadoras que também ocorrem na cultura (BUENO et al., 2011).
O controle químico é a tática mais utilizada pelos agricultores no manejo de pragas. Entretanto, é importante considerar que, atualmente, existe uma escassez de informações sobre a eficiência de controle das lagartas de $S$. cosmioides, não havendo nenhum inseticida registrado para esta praga na cultura da soja no Brasil (MAPA, 2013). Além disso, no ano agrícola 2013/2014 há a expectativa do cultivo da cultivar transgênica de soja (Intacta RR2 $\left.\mathrm{Pro}^{\circledR}\right)$, que expressa a proteína Cry $1 \mathrm{Ac}$ da bactéria Bacillus thuringiensis Berliner, pelos produtores brasileiros visando ao controle de algumas espécies de lagartas desfolhadoras. No entanto, de acordo com Santos et al. (2009), essa proteína apresenta baixa toxicidade a lagartas de $S$. cosmioides, e provavelmente essa tecnologia não será eficiente para reduzir sua população na cultura da soja.

Como alternativa ao controle dessa praga, o uso de plantas resistentes pode constituir uma viável ferramenta dentro dos preceitos do Manejo Integrado de Pragas, já que, dependendo do grau de resistência expresso, pode reduzir suas populações abaixo do nível de dano econômico, não promover desequilíbrio no agroecossistema, não causar aumento no custo de produção e ser compatível com os demais métodos de controle (BOIÇA JÚNIOR et al., 2012).

Tendo em vista a importância de $S$. cosmioides nos últimos anos devido, aos prejuízos econômicos causados na cultura da soja, ausência de inseticidas registrados para seu controle, bem como a falta de informações a respeito de genótipos resistentes a esse inseto, o objetivo desse trabalho foi determinar os tipos de resistência em diferentes genótipos de soja a $S$. cosmioides. 


\section{Material e Métodos}

Os experimentos foram conduzidos na Faculdade de Ciências Agrárias e Veterinárias - FCAV/UNESP, Jaboticabal, SP, no Departamento de Fitossanidade, Laboratório de Resistência de Plantas a Insetos, sob condições de temperatura: $25 \pm 1{ }^{\circ} \mathrm{C}$; umidade relativa: $70 \pm 10 \%$; e fotofase: 12 horas.

As lagartas de $S$. cosmioides utilizadas nos experimentos foram provenientes da criação estoque mantida em laboratório com dieta artificial preparada de acordo com a metodologia de Greene, Leppla e Dickerson (1976), à base de feijão, germe de trigo, farelo de soja, caseína e levedura de cerveja.

Para os ensaios, devido à falta de informações a respeito de variedades resistentes a $S$. cosmioides, foram utilizados os genótipos 'IAC 100' e 'BR 16' (PIUBELLI et al., 2005) como padrões de resistência e suscetibilidade, respectivamente, com base em resultados obtidos com a lagarta-da-soja. Os demais genótipos testados foram: 'Dowling', PI 227687, PI 274454, 'IGRA RA 626 RR', PI 227682, 'BRSGO 8360', 'IGRA RA 516 RR' e 'P $98 Y 11$ RR'.

Não preferência para alimentação de lagartas de Spodoptera cosmioides por genótipos de soja com e sem chance de escolha

No teste de não preferência para alimentação com chance de escolha, foram coletadas folhas de plantas de soja no estádio V5 (FEHR; CAVINESS, 1977) cultivadas em casa de vegetação lavadas em solução de água destilada e hipoclorito de sódio a $0,5 \%$ e, por meio de um vazador, preparados discos foliares de $2,5 \mathrm{~cm}$ de diâmetro, os quais foram colocados em placas de acrílico de 14,0 $\mathrm{cm}$ de diâmetro contendo papel filtro levemente umedecido com água destilada. Os discos foliares foram acondicionados de forma equidistantes entre si e próximos à borda da placa, onde cada disco foliar representou um tratamento (genótipo).

Em seguida, foram liberadas duas lagartas recém-eclodidas de $S$. cosmioides por genótipo, em um total de 20 por placa no centro das placas. Também, foi avaliada a preferência alimentar de lagartas de terceiro ínstar pelos genótipos de soja, e nesse teste, uma lagarta de terceiro ínstar por genótipo foi liberada no centro das placas. Foi utilizado o delineamento de blocos ao acaso, com 10 tratamentos (genótipos) e 10 repetições, onde cada repetição foi representada por uma placa.

Foi avaliada a atratividade das lagartas de terceiro ínstar em relação aos diferentes genótipos a 1, 3, 5, $10,15,30,60,120,360,720$ e 1440 minutos após a liberação dos insetos, e a 1, 3, 5, 10, 15, 30, 60, 120, $360,720,1440,1800,2160$ e 2880 minutos para as lagartas recém-eclodidas. As lagartas utilizadas nesse teste foram mantidas em dieta artificial até atingirem o terceiro ínstar. Além deste parâmetro, a área foliar consumida (A.F.C.) também foi avaliada ao término dos ensaios, por meio de um medidor de área foliar eletrônico, modelo LI-COR $3100 \mathrm{~A}^{\circledR}$. Para isso, a sobra dos discos após a alimentação das lagartas foi conduzida ao medidor de área foliar e, pela diferença da área total do disco foliar e da sobra de alimentação obteve-se a área foliar consumida pelos insetos. A determinação do consumo de área foliar para as lagartas recém-eclodidas foi feita a partir da avaliação visual, pois as lagartas apenas raspavam a face superior da folha, impossibilitando a medição através do medidor de área foliar.

No teste de não preferência para alimentação sem chance de escolha, foi utilizado apenas um disco foliar (genótipo) por placa de Petri de 9,0 cm de diâmetro, onde foram liberadas duas lagartas de primeiro instar em cada placa, enquanto para a avaliação de lagartas de terceiro instar, uma lagarta foi liberada por placa. Utilizou-se o delineamento experimental inteiramente casualizado, com 10 tratamentos (genótipos) e 10 repetições, onde cada repetição foi representada por uma placa de Petri.

A área foliar fornecida, o tempo de avaliação e a obtenção do consumo pelas lagartas foram semelhantes àquelas que foram realizadas no teste com chance de escolha. 
Antibiose em genótipos de soja a Spodoptera cosmioides

A avaliação dos parâmetros biológicos de $S$. cosmioides foi conduzida em placas de Petri de 9,0 $\mathrm{cm}$ de diâmetro contendo papel filtro levemente umedecido com água destilada, onde foram transferidas lagartas recém-eclodidas provenientes da criação estoque, na proporção de uma por placa, acompanhando-se todo o ciclo biológico do inseto. Folhas de soja previamente lavadas em solução de água destilada e hipoclorito de sódio a $0,5 \%$ foram oferecidas ad libitum durante todo o período larval, as quais foram repostas no interior das placas à medida que as lagartas as consumiam. As placas de Petri foram vedadas durante os primeiros dias com filme plástico PVC para se evitar a fuga das lagartas durante o experimento. Foi utilizado o delineamento experimental inteiramente casualizado, com 10 tratamentos (genótipos) e 30 repetições.

Realizou-se a retirada dos excrementos das lagartas no interior das placas, diariamente, bem como a umectação ou troca do papel filtro. Quando os insetos atingiram a fase de pupa, interrompeuse o oferecimento de folhas. Durante a fase adulta, as mariposas não receberam qualquer tipo de alimentação a fim de serem verificados apenas os efeitos dos genótipos de soja no desenvolvimento de $S$. cosmioides.

Os seguintes parâmetros biológicos foram avaliados: período larval; viabilidade larval; período pupal; viabilidade pupal; período total; viabilidade total; razão sexual; peso de lagartas com 12 dias de idade; peso de pupas com 24 horas de idade; razão sexual; e longevidade dos adultos.

\section{Análise estatística}

Os resultados obtidos foram submetidos à análise de variância (ANOVA) através do teste $F$, e quando significativa, as médias foram comparadas pelo teste de Tukey $(P=0,05)$. Os dados de atratividade das lagartas com e sem chance de escolha, área foliar consumida, período larval, pupal e total, peso de lagartas com 12 dias de idade, peso de pupas com 24 horas de idade, razão sexual e longevidade dos adultos foram transformados em $(x+0,5)^{1 / 2}$, os dados de viabilidade pupal foram transformados em $\operatorname{arcoseno}(\mathrm{x} / 100)^{1 / 2}$ e os dados de viabilidade larval e total em $\log (\mathrm{x}+5)$ após serem analisados quanto à sua normalidade pelo teste de Kolmogorov-Smirnov e homocedasticidade pelo teste de Bartlett.

\section{Resultados e Discussão}

Não preferência para alimentação de lagartas de Spodoptera cosmioides por genótipos de soja com e sem chance de escolha

Analisando-se os resultados obtidos no teste de não preferência para alimentação com chance de escolha de lagartas recém-eclodidas, pode-se observar que não houve diferenças significativas na atratividade dos insetos em todos os intervalos de tempo avaliados (Tabela 1). Em relação à área foliar consumida, também não houve diferença significativa entre os genótipos (Tabela 1).

No teste sem chance de escolha, verificou-se que houve diferenças significativas na atratividade entre os genótipos aos 15, 60 e 1440 minutos após a liberação das lagartas recém-eclodidas. Nesses tempos, de modo geral, o genótipo 'IGRA RA 626 RR' foi o mais atrativo, enquanto menor número de lagartas foi observado em P 98Y11 RR (Tabela 2).

Ao se observar a área foliar consumida por $S$. cosmioides, verificou-se diferença significativa entre os genótipos (Tabela 2), sendo que 'IGRA RA 516 RR' $\left(0,18 \mathrm{~cm}^{2}\right)$, PI $274454\left(0,21 \mathrm{~cm}^{2}\right)$ e 'Dowling' $\left(0,23 \mathrm{~cm}^{2}\right)$ se destacaram como os menos consumidos, enquanto o genótipo IGRA RA 626 $\mathrm{RR}$ apresentou o maior consumo foliar $\left(0,88 \mathrm{~cm}^{2}\right)$.

Analisando-se a atratividade de lagartas de $3^{\circ}$ ínstar de $S$. cosmioides em relação aos genótipos de soja, em teste com chance de escolha (Tabela 3), pode-se observar que houve diferença significativa apenas aos 1440 minutos após o início do ensaio. 
Menor número de lagartas atraídas ocorreu em 'IAC 100 ' (0,40 insetos), enquanto PI 274454, 'Dowling' e 'IGRA RA 626 RR' foram os mais atrativos a $S$. cosmioides (1,00 insetos). Nos demais tempos avaliados, todos os genótipos apresentaram-se de forma semelhante para a atratividade das lagartas.

A área foliar consumida por lagartas de $3^{\circ}$ ínstar de $S$. cosmioides não diferiu entre os genótipos de soja no teste com chance de escolha (Tabela 3).

Para o teste sem chance de escolha, não houve diferenças significativas na atratividade durante todo o período de avaliação, bem como na área foliar consumida pelas lagartas de S. cosmioides (Tabela 4).

A preferência para alimentação de um inseto fitófago a um determinado genótipo varia de acordo com os estímulos provenientes da planta, os quais podem ser positivos ou negativos, de natureza química (aleloquímicos), física (cor) ou morfológica (pilosidade, dureza, textura, espessura, dimensões de estruturas). Vale-se ressaltar ainda, que ambos os estímulos, positivos e negativos, estão presentes na planta, de modo que a resposta do inseto em relação à mesma depende do estímulo que sobrepujar o outro (BOIÇA JÚNIOR et al., 2012). Nesse sentido, e se baseando nos resultados obtidos nos ensaios com lagartas recém-eclodidas e de $3^{\circ}$ ínstar de $S$. cosmioides, possivelmente nenhum dos genótipos de soja testados apresentam características de resistência do tipo não preferência a essa espécie nas condições testadas, apesar de o genótipo utilizado como padrão de resistência nos ensaios demonstrar essa característica a outras espécies de lagartas desfolhadoras.

Por exemplo, Hoffmann-Campo, Mazzarin e Lustosa (1994), avaliando a preferência para alimentação de Anticarsia gemmatalis Hübner por genótipos de soja, relataram que 'IAC 100' se comportou como resistente em relação aos genótipos 'BR 79-15149', 'Davis' e 'BR 80-25896'. Lourenção et al. (2000), em experimentos realizados em campo com genótipos de soja de ciclo precoce e semiprecoce, observaram que 'IAC 100' apresentou a menor média de porcentagem de área foliar cortada por A. gemmatalis, demonstrando possuir resistência do tipo não preferência para alimentação à lagarta-da-soja. Souza et al. (2012), avaliando a não preferência para alimentação de lagartas de Spodoptera eridania (Cramer) em genótipos de soja em laboratório, relataram que 'IAC 100' apresentou alto grau de resistência ao inseto em testes com e sem chance de escolha. 


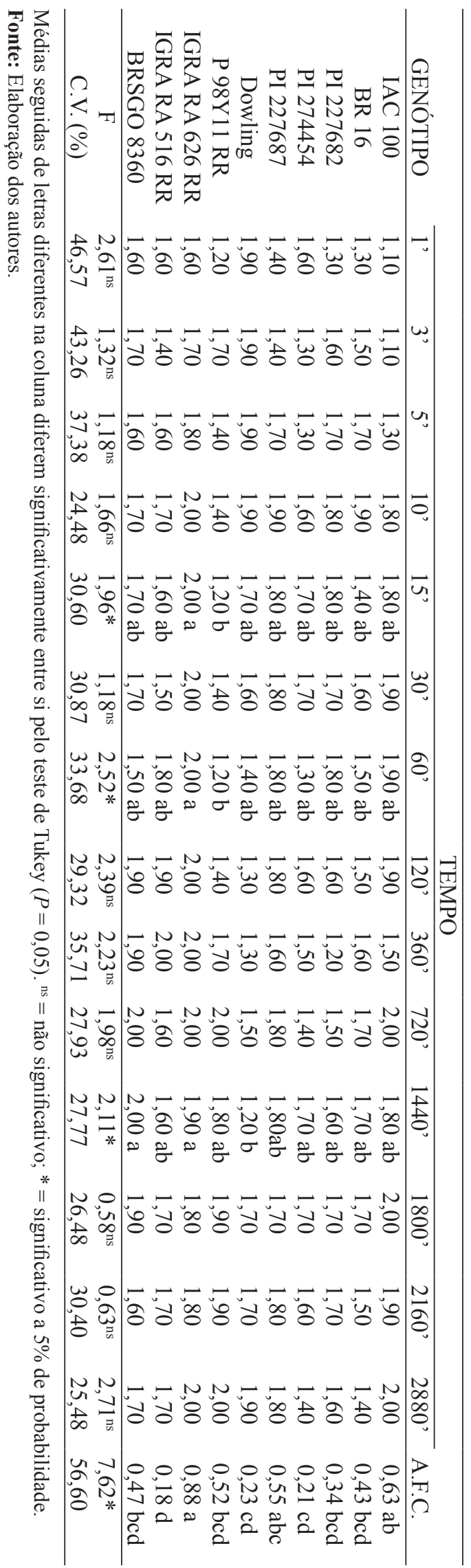

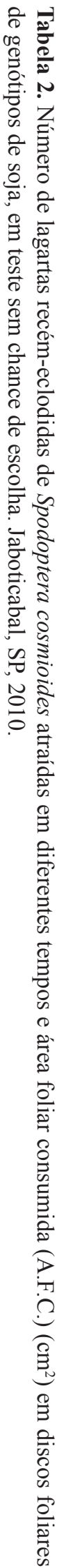

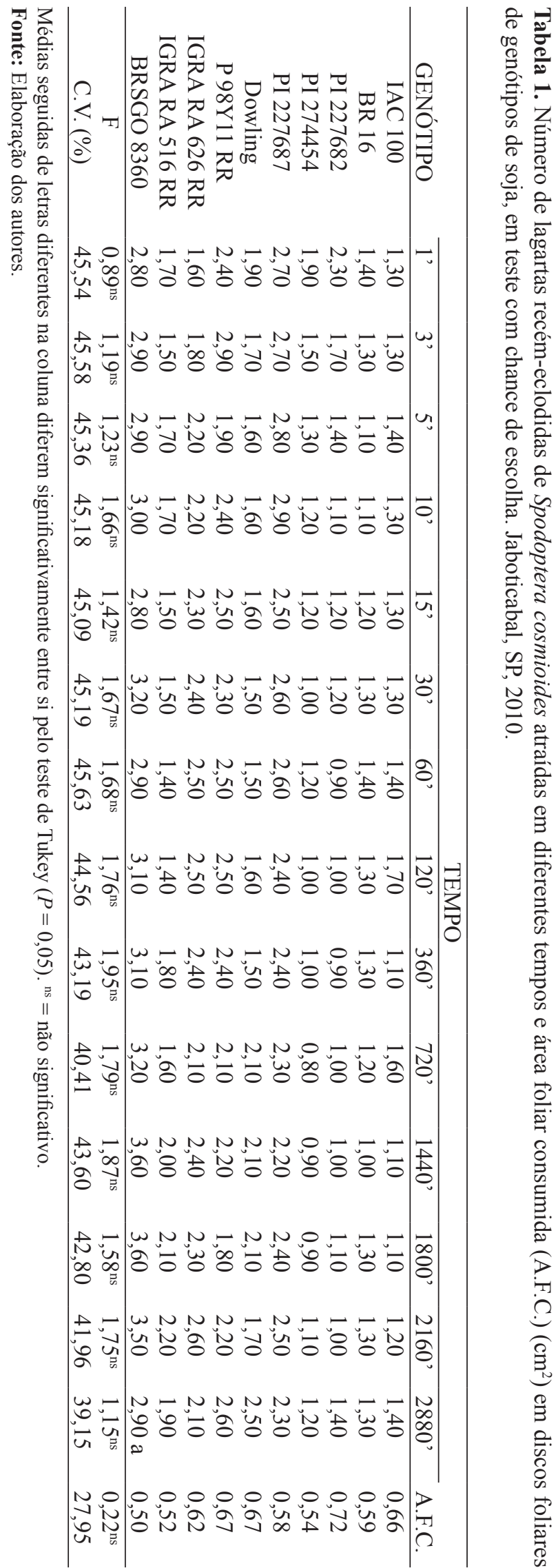




중

元

ปै ก

.

ปิ

$\checkmark$.

a

음

ธิ త્อ

0

흐 임

药

의

음

జ

预

을

过

竞

ले

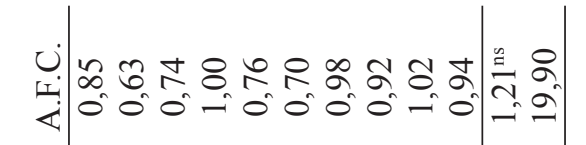

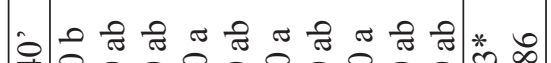

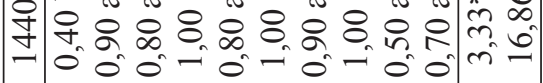

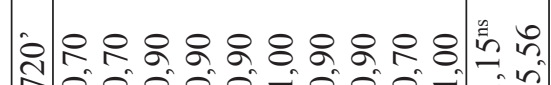

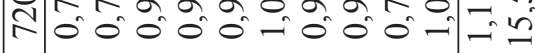

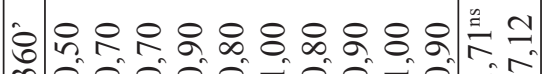

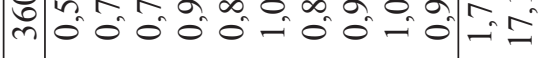

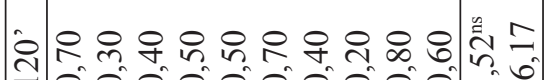

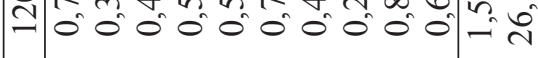

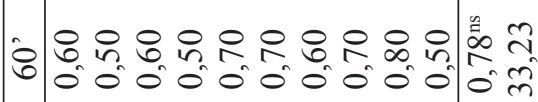

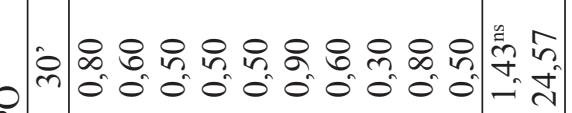

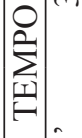

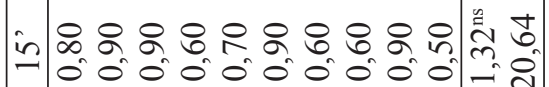

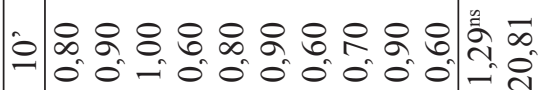

in 0.8 .888 .88 .80

$\ln 000,100,000$

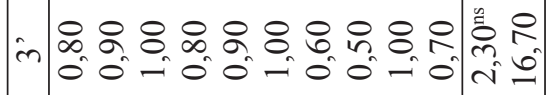

요요요은

- or 0000000 on

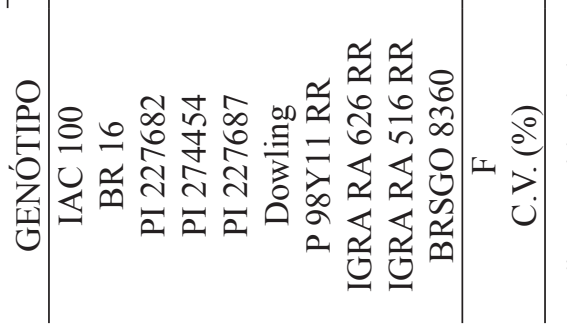

ข

莡

:

ฮี

है

כ)

近

울

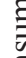

8

흥

皮

.ั.

:

$\stackrel{0}{0}$

छี

造

䒕

ปै

零

ปิ

ำ

흔

के

ช

홍 음

$\cong$

in 주

음

ส

预

응

离 $\frac{0}{0}$

言告

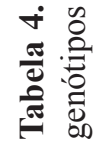

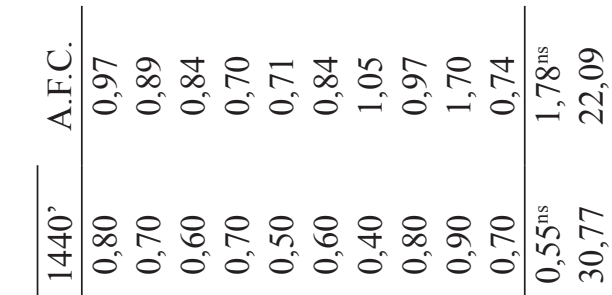

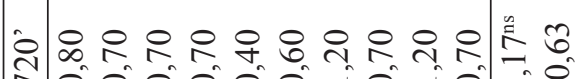

तै 00000000000

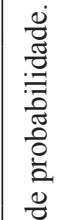

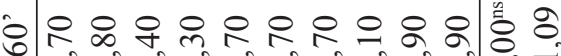

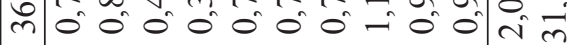

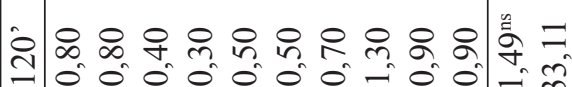

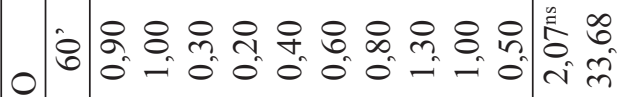

$\sum_{\text {突 }}^{\circ}$

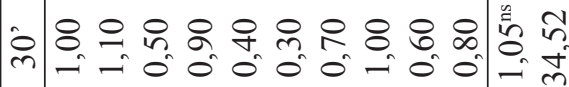

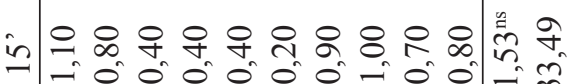

$\begin{array}{lllllllllll}0 & 0 & 0 & 0 & 0 & 0 & 0 & 0 & 0\end{array}$

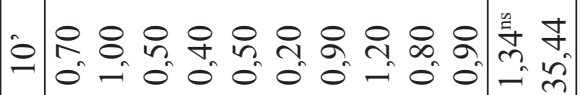

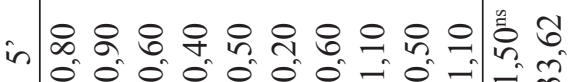

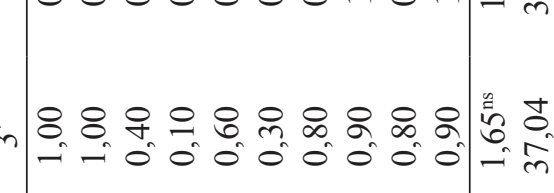

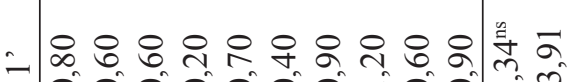

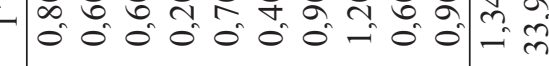

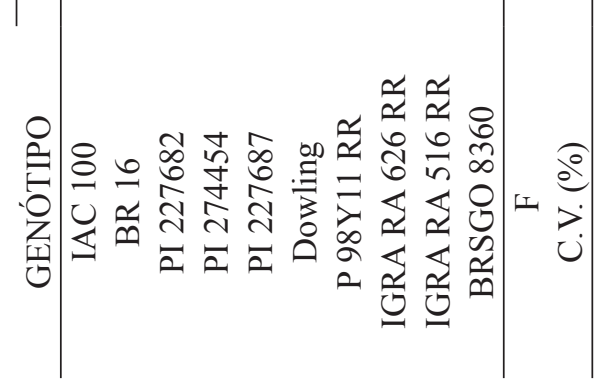
 
Antibiose em genótipos de soja a Spodoptera cosmioides

Foram verificadas diferenças significativas entre as médias da duração da fase larval nos genótipos de soja estudados (Tabela 5). O período larval de $S$. cosmioides foi significativamente maior nos insetos alimentados com folhas do genótipo 'Dowling' (29,14 dias), indicando que este genótipo foi pouco adequado para o desenvolvimento deste estágio da praga. O menor período da fase larval foi observado nos genótipos 'IGRA RA 626 RR' (20,53 dias) e 'P 98Y11 RR' (23,33 dias) (Tabela 5).

O prolongamento da fase larval é um indicativo de menor adequação do substrato alimentar, em consequência da provável presença de compostos químicos que conferem resistência ao inseto (SILVEIRA; VENDRAMIM; ROSSETTO, 1997).

É importante ressaltar que as lagartas de $S$. cosmioides alimentadas com folhas dos genótipos
'IAC 100', PI 227682 e PI 227687 não foram avaliadas quanto à duração do período larval em função do número insuficiente de indivíduos restantes para análise estatística (Tabela 5), e, portanto, também não foram incluídos para avaliação do período e viabilidade pupal, período total, peso de pupas, razão sexual e longevidade de adultos (Tabelas 5 e 6).

A viabilidade da fase larval representa um dos parâmetros biológicos mais importantes do crescimento populacional de insetos (DAHMS, 1972). Nessa pesquisa, a viabilidade de lagartas de S. cosmioides alimentadas com folhas dos genótipos de soja variou significativamente entre os genótipos (Tabela 5). As menores viabilidades foram observadas nos genótipos PI 227682 (3,33\%), PI 227687 (3,33\%) e 'IAC 100' (6,67\%) e as maiores em 'IGRA RA 626 RR', (50,00\%) 'IGRA RA 516 RR' (50,00\%), PI 274454 (50,00\%), 'BR 16' (43,33\%) e 'P 98Y11 RR' (43,33\%) (Tabela 5).

Tabela 5. Duração dos períodos (dias) e viabilidades (\%) larval, pupal e total (eclosão da larva à emergência do adulto) de Spodoptera cosmioides alimentada com folhas de genótipos de soja. Jaboticabal, SP, 2010.

\begin{tabular}{|c|c|c|c|c|c|c|}
\hline \multirow{2}{*}{ GENÓTIPO } & \multicolumn{2}{|c|}{ Fase larval } & \multicolumn{2}{|c|}{ Fase pupal } & \multicolumn{2}{|c|}{ Total } \\
\hline & Período & Viabilidade & Período & Viabilidade & Período & Viabilidade \\
\hline IAC 100 & -1 & $6,67 \mathrm{ab}$ & - & - & - & - \\
\hline BR 16 & $24,08 \mathrm{~b}$ & $43,33 \mathrm{c}$ & $13,85 \mathrm{a}$ & 100,00 & $37,92 \mathrm{ab}$ & 60,45 \\
\hline PI 227682 & - & $3,33 \mathrm{a}$ & - & - & - & - \\
\hline PI 274454 & $24,27 b$ & $50,00 \mathrm{c}$ & $13,61 \mathrm{a}$ & 86,67 & $38,08 \mathrm{ab}$ & 62,22 \\
\hline PI 227687 & - & $3,33 \mathrm{a}$ & - & - & - & - \\
\hline Dowling & $29,14 \mathrm{c}$ & $23,33 a b c$ & $14,28 \mathrm{ab}$ & 100,00 & $43,43 \mathrm{c}$ & 37,84 \\
\hline P 98Y11 RR & $23,33 \mathrm{a}$ & $43,33 \mathrm{c}$ & $17,54 \mathrm{c}$ & 91,67 & $40,91 \mathrm{bc}$ & 57,14 \\
\hline IGRA RA 626 RR & $20,53 \mathrm{a}$ & $50,00 \mathrm{c}$ & $15,87 \mathrm{abc}$ & 100,00 & $36,40 \mathrm{a}$ & 66,67 \\
\hline IGRA RA 516 RR & $24,14 \mathrm{~b}$ & $50,00 \mathrm{c}$ & $17,23 \mathrm{bc}$ & 92,86 & $41,32 \mathrm{bc}$ & 63,64 \\
\hline BRSGO 8360 & $22,33 \mathrm{ab}$ & $40,00 \mathrm{bc}$ & $15,17 \mathrm{abc}$ & 100,00 & $37,50 \mathrm{ab}$ & 57,14 \\
\hline $\mathrm{F}$ & $15,97 * *$ & $5,75 * *$ & $4,84 * *$ & $0,90^{\mathrm{ns}}$ & $5,96 * *$ & $1,44^{\mathrm{ns}}$ \\
\hline C.V. $(\%)$ & 4,15 & 4,78 & 7,78 & 22,02 & 4,19 & 5,27 \\
\hline
\end{tabular}

Médias seguidas de letras diferentes na coluna diferem significativamente entre si pelo teste de Tukey $(P=0,05)$. ${ }^{\text {ns }}=$ não significativo; $*=$ significativo a $5 \%$ de probabilidade; $* *=$ significativo a $1 \%$ de probabilidade. ${ }^{1}$ Dados insuficientes de repetições para análise estatística.

Fonte: Elaboração dos autores. 
Smith e Gilman (1981) observaram mortalidade de $100 \%$ de lagartas de Pseudoplusia includens (Walker) quando alimentadas com folhas do genótipo PI 227687, sendo que 30\% das mesmas morreram durante os primeiros sete dias e $57 \%$ do $18^{\circ}$ ao $25^{\circ}$ dia de avaliação. Yanes Júnior e Boethel (1983) também verificaram $100 \%$ de lagartas de P. includens mortas quando alimentadas com PI 227687, como também Hatchett, Beland e Hartwig (1976) encontraram o mesmo índice de mortalidade para Helicoverpa zea (Boddie) e Heliothis virescens (Fabricius) criadas com esse genótipo.

Foram detectadas diferenças significativas entre as médias relativas à duração da fase pupal nos genótipos de soja estudados. A duração do período pupal foi maior no genótipo 'P 98Y11 RR' (17,54 dias), não diferindo, no entanto, de 'IGRA RA 516 RR' (17,23 dias), 'IGRA RA 626 RR' (15,87 dias) e 'BRSGO 8360' (15,17 dias) (Tabela 5). O menor período da fase de pupa foi observado nos genótipos PI 274454 (13,61 dias) e 'BR16' (13,85 dias) (Tabela 5).

Quanto à viabilidade da fase pupal, nenhuma diferença significativa foi observada entre os genótipos, variando de 86,67 a 100\% (Tabela 5).

Lagartas alimentadas com folhas do genótipo 'Dowling', apresentaram o ciclo biológico maior (43,43 dias), diferindo de 'IGRA RA 626 RR', que induziu a menor duração (36,40 dias) (Tabela 5).

Não foi possível realizar a análise estatística para os genótipos PI 227682, PI 227687 e 'IAC 100' em vários parâmetros biológicos de $S$. cosmioides devido à alta mortalidade larval, sendo observadas porcentagens de viabilidade do período de larva a adulto nulas para esses genótipos (Tabela 5), enquanto para os demais, não foi verificada diferença significativa.

Os genótipos 'Dowling' e 'IGRA RA 626 RR' proporcionaram o maior de peso de lagartas com 12 dias de idade (274,29 e 250,63 mg, respectivamente), enquanto os menores valores foram observados em PI 227682 (37,65 mg), PI 227687 (38,00 mg) e 'IAC 100' (85,56 mg) (Tabela 6). Smith e Gilman (1981) observaram lagartas de P. includens com 14 dias menos pesadas quando alimentadas com folhas do genótipo PI 227687, quando comparadas àquelas criadas com outros seis genótipos de soja. Yanes Júnior. e Boethel (1983) também verificaram menor consumo e consequentemente menor peso da lagarta falsa-medideira alimentada com PI 227687 em comparação com o genótipo 'Davis'. Oliveira, Hoffmann-Campo e Mazzarin (1993), avaliando sete genótipos de soja, observaram que 'IAC 100' provocou aumento no desenvolvimento e redução do peso de $A$. gemmatalis.

Os pesos de pupas com 24 horas de idade provenientes de lagartas alimentadas com folhas de diferentes genótipos de soja apresentaram diferenças significativas (Tabela 6). O genótipo 'IGRA RA 626 RR' proporcionou maior ganho de peso de pupas $(407,33 \mathrm{mg})$, enquanto a menor média para esse parâmetro foi observada em 'IGRA RA 516 RR' (288,57 mg) (Tabela 6). Machado et al. (1999) observaram menor peso de pupas de $A$. gemmatalis cujas lagartas se alimentaram de folhas do genótipo 'IAC 100' comparativamente com 'IAC 17', 'FT Estrela' e 'Emgopa 316'. Castiglioni e Vendramim (1996) também verificaram resultados semelhantes quando esse mesmo inseto foi criado com o genótipo de soja 'IAC 100'.

Não foram detectadas diferenças significativas em relação à razão sexual, demonstrando que a alimentação das lagartas com folhas dos diferentes genótipos de soja não influenciou na proporção de indivíduos machos e fềmeas (Tabela 6), bem como não afetou a longevidade dos adultos, a qual variou de 3,00 a 4,46 dias, sem alimentação (Tabela 6). 
Tabela 6. Peso (mg) de lagartas com 12 dias de idade e de pupas com 24 horas de idade, razão sexual e longevidade (dias) de adultos de Spodoptera cosmioides alimentada com folhas de genótipos de soja. Jaboticabal, SP, 2010.

\begin{tabular}{|c|c|c|c|c|}
\hline \multirow{2}{*}{ GENÓTIPO } & \multicolumn{2}{|c|}{ Peso } & \multirow{2}{*}{$\begin{array}{l}\text { Razão } \\
\text { Sexual }\end{array}$} & \multirow{2}{*}{ Longevidade } \\
\hline & Larval & Pupal & & \\
\hline IAC 100 & $85,56 \mathrm{a}$ & -1 & - & - \\
\hline BR 16 & $109,41 \mathrm{ab}$ & $373,85 \mathrm{bc}$ & 0,61 & 3,54 \\
\hline PI 227682 & $37,65 \mathrm{a}$ & - & - & - \\
\hline PI 274454 & $123,16 \mathrm{ab}$ & $312,67 \mathrm{ab}$ & 0,47 & 3,00 \\
\hline PI 227687 & $38,00 \mathrm{a}$ & - & - & - \\
\hline Dowling & $274,29 \mathrm{c}$ & $370,00 \mathrm{bc}$ & 0,43 & 3,71 \\
\hline P 98Y11 RR & $112,14 \mathrm{ab}$ & $368,33 \mathrm{bc}$ & 0,58 & 4,09 \\
\hline IGRA RA 626 RR & $250,63 \mathrm{bc}$ & $407,33 \mathrm{c}$ & 0,40 & 3,40 \\
\hline IGRA RA 516 RR & $132,35 \mathrm{ab}$ & $288,57 \mathrm{a}$ & 0,57 & 4,46 \\
\hline BRSGO 8360 & $153,33 \mathrm{abc}$ & $345,83 \mathrm{abc}$ & 0,42 & 3,33 \\
\hline $\mathrm{F}$ & $8,40 * *$ & $7,94 * *$ & $0,39^{\mathrm{ns}}$ & $2,22^{\mathrm{ns}}$ \\
\hline C.V. $(\%)$ & 7,07 & 3,24 & 27,54 & 14,13 \\
\hline
\end{tabular}

Médias seguidas de letras diferentes na coluna diferem significativamente entre si pelo teste de Tukey $(P=0,05)$. ${ }^{\text {ns }}=$ não significativo; $*=$ significativo a $5 \%$ de probabilidade; $* *=$ significativo a $1 \%$ de probabilidade. ${ }^{~}$ Dados insuficientes de repetições para análise estatística.

Fonte: Elaboração dos autores.

É evidente que os genótipos PI 227687, PI 227682 e IAC 100 apresentam fatores de natureza química e/ou morfológica responsáveis pela manifestação da resistência a $S$. cosmioides, evidenciados principalmente pela alta mortalidade e redução do peso larval, e que estas características das plantas também foram responsáveis pela resistência a outras pragas, como já relatado em outros trabalhos na literatura.

Piubelli et al. (2005) estudando extratos foliares de 'IAC 100' e PI 227687 na alimentação da lagarta-da-soja, identificaram e quantificaram os flavonoides rutina e genistina, substâncias que desempenham função de defesa das plantas a insetos-praga. Lambert e Kilen (1984) verificaram que o genótipo de soja PI 227687 reduziu a taxa de desenvolvimento larval de A. gemmatalis. Machado et al. (1999) verificaram maior duração do período larval de A. gemmatalis quando as lagartas se alimentaram de folhas de 'IAC 100'.

Reynolds, Smith e Kester (1984) sugerem que, além da presença de um fator de deterrência ou ausência de estimulante para alimentação em PI 227687, também ocorra outro mecanismo de resistência que contribui para a redução da taxa de crescimento dos insetos alimentados com esse genótipo, podendo ser, por exemplo, desbalanços nas concentrações de nutrientes. Tester (1977) relatou porcentagem de $26,00 \%$ mais baixa de proteína no genótipo PI 227687 em comparação com a cultivar Davis.

Reynolds e Smith (1985) observaram menores taxas de crescimento de larvas de sexto ínstar de $P$. includens quando alimentadas com folhas do genótipo PI 227687 previamente injuriadas em comparação com folhas sem injúrias. Os autores sugerem a existência de um mecanismo nesse genótipo o qual é eliciado apenas mediante injúria mecânica do tecido vegetal, proporcionando um acúmulo de fitoalexinas, provavelmente responsáveis pela resistência ao inseto.

Hulburt, Boerma e All (2004) observaram menor ganho de peso de lagartas de H. zea e Spodoptera exigua (Hübner) alimentadas com PI 227687, e menores porcentagens de desfolhamento em plantas desse genótipo causadas por $P$. includens e as outras duas espécies mencionadas. Os autores correlacionaram esse menor metabolismo à presença 
de tricomas pontiagudos presentes em PI 227687 em comparação com aqueles de ponta arredondada no genótipo 'Cobb', o qual proporcionou o maior ganho de peso às lagartas e apresentou o maior índice de desfolha.

Desse modo, os altos graus de resistência to tipo antibiose a $S$. cosmioides encontrados nos genótipos PI 227687, PI 227682 e 'IAC 100' no presente trabalho representam informação importante que pode contribuir para a utilização futura desses genótipos em programas de melhoramento da soja visando ao desenvolvimento de plantas que apresentem ao mesmo tempo boas características agronômicas de alta produtividade e resistência a essa praga.

\section{Conclusões}

- Os genótipos de soja 'Dowling', PI 274454, 'IGRA RA 626 RR', 'BRSGO 8360', 'IGRA RA 516 RR', 'P $98 Y 11$ RR', PI 227682, PI 227687, 'IAC 100' e BR 16 não apresentam resistência do tipo não preferência para alimentação a lagartas recém-eclodidas e de $3^{\circ}$ ínstar de S. cosmioides;

- Os genótipos PI 227682, PI 227687 e 'IAC 100' destacaram-se como portadores de resistência do tipo antibiose a $S$. cosmioides.

\section{Referências}

BOIÇA JÚNIOR, A. L.; SOUZA, B. H. S.; BOTTEGA, D. B.; RODRIGUES, N. E. L.; COSTA, E. N.; RIBEIRO, Z. A. Resistência de plantas e produtos naturais no controle de pragas em culturas agrícolas. In: BUSOLI, A. C.; GRIGOLLI, J. F. J.; SOUZA, L. A.; KUBOTA, M. M.; COSTA, E. N.; SANTOS, L. A. O.; NETTO, J. C.; VIANA, M. A. (Ed.). Tópicos em entomologia agrícola - V. Jaboticabal: Gráfica Multipress Ltda., 2012. p. 139158.

BUENO, R. C. O. F.; BUENO, A. F.; MOSCARDI, F.; PARRA, J. R. P.; HOFFMANN-CAMPO, C. B. Lepidopteran larva consumption of soybean foliage: basis for developing multiple-species economic thresholds for pest management decisions. Pest Management Science, Sussex, v. 67, n. 2, p. 170-174, 2011.
CASTIGLIONI, E. A. R.; VENDRAMIM, J. D. Efeitos de genótipos de soja no desenvolvimento de Anticarsia gemmatalis Hübner (Lepidoptera: Noctuidae). Anais da Sociedade Entomológica do Brasil, Londrina, v. 25, n. 3, p. 411-416, 1996.

COMPANHIA NACIONAL DE ABASTECIMENTO - CONAB. Acompanhamento da safra brasileira. Grãos, quarto levantamento. Brasília: Conab, jan. 2014. Disponível em: <http://www.conab.gov.br/OlalaCMS/ uploads/arquivos/14_01_10_15_07_19_boletim_graos_ janeiro_2014.pdf>. Acesso em: 29 jan. 2014.

DAHMS, R. G. The role of host plant resistance in integrated insect control. In: JOTWANI, M. G.; YOUNG, W. R. (Ed.). Control of sorghum shoot fly. New Delhi: Oxford \& IBH, 1972. p. 152-167.

FEHR, W. R.; CAVINESS, C. E. Stages of soybean development. Ames: Iowa State University of Science and Technology, 1977. 11 p. (Special Report, 80).

GREENE, G. L.; LEPPLA, N. C.; DICKERSON, W. A. Velvetbean caterpillar. A rearing procedure and artificial medium. Journal of Economic Entomology, Lanham, v. 69, n, 4, p. 447-448, 1976.

HATCHETT, J. H.; BELAND, G. L.; HARTWIG, E. E. Leaf-feeding resistance to bollworm and tobacco budworm in three soybean plant introductions. Crop Science, Madison, v. 16, n. 2, p. 277-280, 1976.

HOFFMANN-CAMPO, C. B.; MAZZARIN, R. M.; LUSTOSA, P. R. Mecanismos de resistência de genótipos de soja: teste de não-preferência para Anticarsia gemmatalis Hübner, 1818 (Lep.: Noctuidae). Pesquisa Agropecuária Brasileira, Brasília, v. 29, n. 4, p. 513-519, 1994.

HULBURT, D. J.; BOERMA, H. R.; ALL, J. N. Effect of pubescence tip on soybean resistance to lepidopteran insects. Journal of Economic Entomology, Lanham, v. 97, n. 2, p. 621-627, 2004.

LAMBERT, L.; KILEN, T. C. Influence of three soybean plant genotypes and their $\mathrm{F}_{1}$ intercrosses on the development of five insect species. Journal of Economic Entomology, Lanham, v. 77, n. 3, p. 622-625, 1984.

LOURENÇÃO, A. L.; PEREIRA, J. C. V. N. A.; MIRANDA, M. A. C.; AMBROSANO, G. M. B. Avaliação de danos causados por percevejos e por lagartas em genótipos de soja de ciclos precoce e semiprecoce. Pesquisa Agropecuária Brasileira, Brasília, v. 35, n. 5, p. 879-886, 2000.

MACHADO, V. O. F.; FERREIRA, G. A.; ROSA, S. R. A.; GARCIA, A. H.; PINHEIRO, J. B.; VELOSO, V. R. S. Aspectos biológicos de Anticarsia gemmatalis Hübner 
(Lepidoptera: Noctuidae) em cultivares de soja (Glycine max Merril). Pesquisa Agropecuária Tropical, Goiânia, v. 29, n. 1, p. 39-41, 1999.

MINISTÉRIO DA AGRICULTURA, PECUÁRIA E ABASTECIMENTO - MAPA. AGROFIT: sistema de agrotóxicos fitossanitários. Brasília: MAPA, 2013. Disponível em: $<$ http://agrofit.agricultura.gov.br/agrofit_ cons/principal_agrofit_cons $>$. Acesso em: 18 fev. 2013.

OLIVEIRA, L. J.; HOFFMANN-CAMPO, C. B.; MAZZARIN, R. M. Aspectos biológicos e nutricionais de Anticarsia gemmatalis Hüb. (Lepidoptera: Noctuidae) em diversos genótipos de soja. Anais da Sociedade Entomológica do Brasil, Londrina, v. 22, n. 33, p. 547552, 1993.

PANIZZI, A. R.; BUENO, A. F.; SILVA, F. A. C. Insetos que atacam vagens e grãos. In: HOFFMANN-CAMPO, C. B.; CORRÊA-FERREIRA, B. S.; MOSCARDI, F. (Ed.). Soja: manejo integrado de insetos e outros artrópodes-praga. Brasília: Embrapa, 2012. p. 335-420.

PIUBELLI, G. C.; HOFFMANN-CAMPO, C. B.; MOSCARDI, F.; MIYAKUBO, S. H.; OLIVEIRA, M. C. N. Are chemical compounds important for soybean resistance to Anticarsia gemmatalis? Journal of Chemical Ecology, New York, v. 31, n. 7, p. 1509-1525, 2005.

REYNOLDS, G. W.; SMITH, C. M. Effects of leaf position, leaf wounding, and plant age of two soybean genotypes on soybean looper (Lepidoptera: Noctuidae) growth. Environmental Entomology, College Park, v. 14, n. 4, p. 475-478, 1985.

REYNOLDS, G. W.; SMITH, C. M.; KESTER, K. M. Reductions in consumption, utilization, and growth rate of soybean looper (Lepidoptera: Noctuidae) larvae fed foliage of soybean genotype PI 227687. Journal of Economic Entomology, Lanham, v. 77, n. 6, p. 13711375, 1984.

SANTOS, K. B.; MENEGUIM, A. M.; SANTOS, W. J.; NEVES, P. M. O. J.; SANTOS, R. B. Characterization of the damage of Spodoptera eridania (Cramer) and Spodoptera cosmioides (Walker) (Lepidoptera: Noctuidae) to structures of cotton plants. Neotropical Entomology, Londrina, v. 39, n. 4, p. 626-631, 2010.
SANTOS, K. B.; NEVES, P. J.; MENEGUIM, A. M.; SANTOS, R. B.; SANTOS, W. J.; VILLAS BOAS, G.; DUMAS, V.; MARTINS, E.; PRAÇA, L. B.; QUEIROZ, P.; BERRY, C.; MONNERAT, R. Selection and characterization of the Bacillus thuringiensis strains toxic to Spodoptera eridania (Cramer), Spodoptera cosmiodes (Walker) and Spodoptera frugiperda (Smith) (Lepidoptera: Noctuidae). Biological Control, Orlando, v. 50, n. 2, p. 157-163, 2009.

SANTOS, W. J. Manejo das pragas do algodão com destaque para o cerrado brasileiro. In: FREIRE, E. C. (Ed.). Algodão no cerrado do Brasil. Brasília: Associação Brasileira dos Produtores de Algodão, 2007. p. 403-478.

SILVEIRA, L. C. P.; VENDRAMIM, J. D.; ROSSETTO, C. J. Efeito de genótipos de milho no desenvolvimento de Spodoptera frugiperda (J. E. Smith). Anais da Sociedade Entomológica do Brasil, Londrina, v. 26, n. 2, p. 291298, 1997.

SMITH, C. M.; GILMAN, D. F. Comparative resistance of multiple insect-resistance soybean genotypes to the soybean looper. Journal of Economic Entomology, Lanham, v. 74, n. 4, p. 400-403, 1981.

SOUZA, B. H. S.; BOIÇA JÚNIOR, A. L.; JANINI, J. C.; SILVA, A. G.; RODRIGUES, N. E. L. No preference for feeding of Spodoptera eridania (Lepidoptera: Noctuidae) on soybean genotypes. Revista Colombiana de Entomología, Santafé de Bogotá, v. 38, n. 2, p. 215 223, 2012.

TESTER, C. F. Constituents of soybean cultivars differing in insect resistance. Phytochemistry, New York, v. 16, n. 12, p. 1899-1901, 1977.

YANES JÚNIOR, J.; BOETHEL, D. J. Effect of a resistant soybean genotype on the development of the soybean looper (Lepidoptera: Noctuidae) and an introduced parasitoid Microplitis demolitor Wilkinson (Hymenoptera: Braconidae). Environmental Entomology, College Park, v. 12, n. 4, p. 1270-1274, 1983. 